\title{
Abriendo Oportunidades: Guía Curricular Plan de Vida 2016-Cuadernillo español
}

Population Council

Follow this and additional works at: https://knowledgecommons.popcouncil.org/departments_sbsr-pgy

Part of the Civic and Community Engagement Commons, Family, Life Course, and Society Commons, and the Gender Equity in Education Commons How does access to this work benefit you? Let us know!

\section{Recommended Citation}

"Abriendo Oportunidades: Guía Curricular Plan de Vida 2016-Cuadernillo español." Guatemala City: Population Council, 2016. 

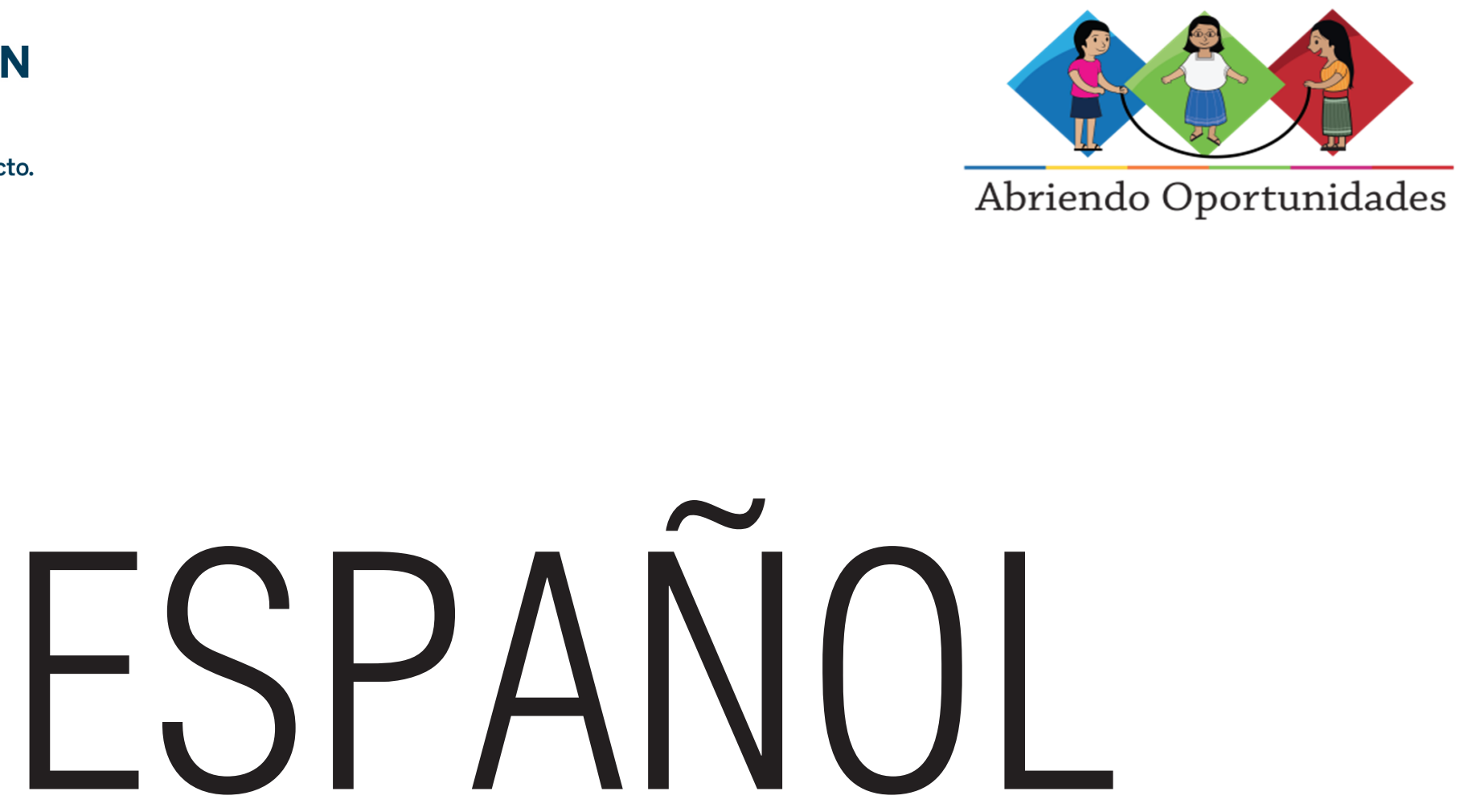

Guía Curricular Plan de Vida 2016 Population Council 
SESIÓN 1 - Logros en mi vida

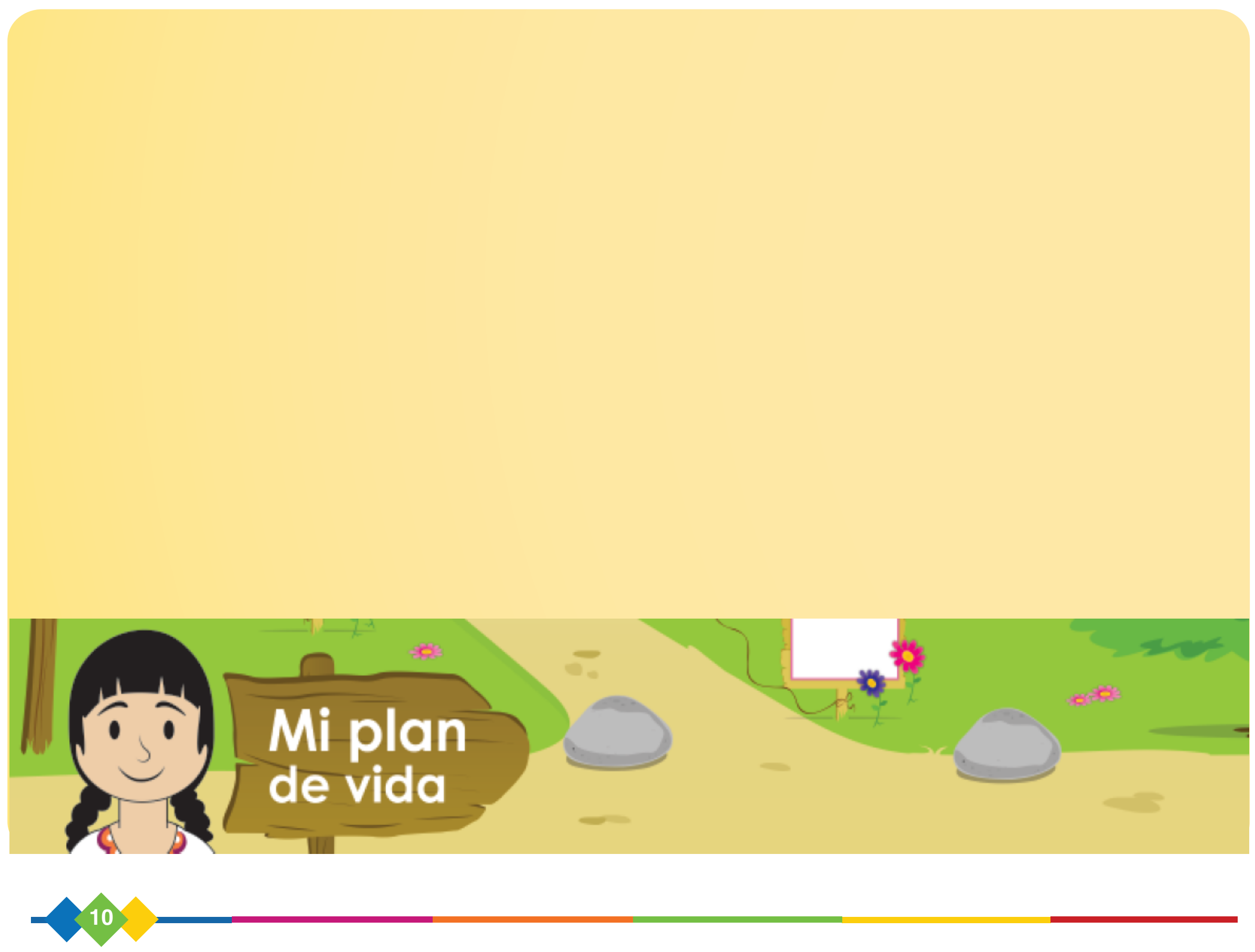




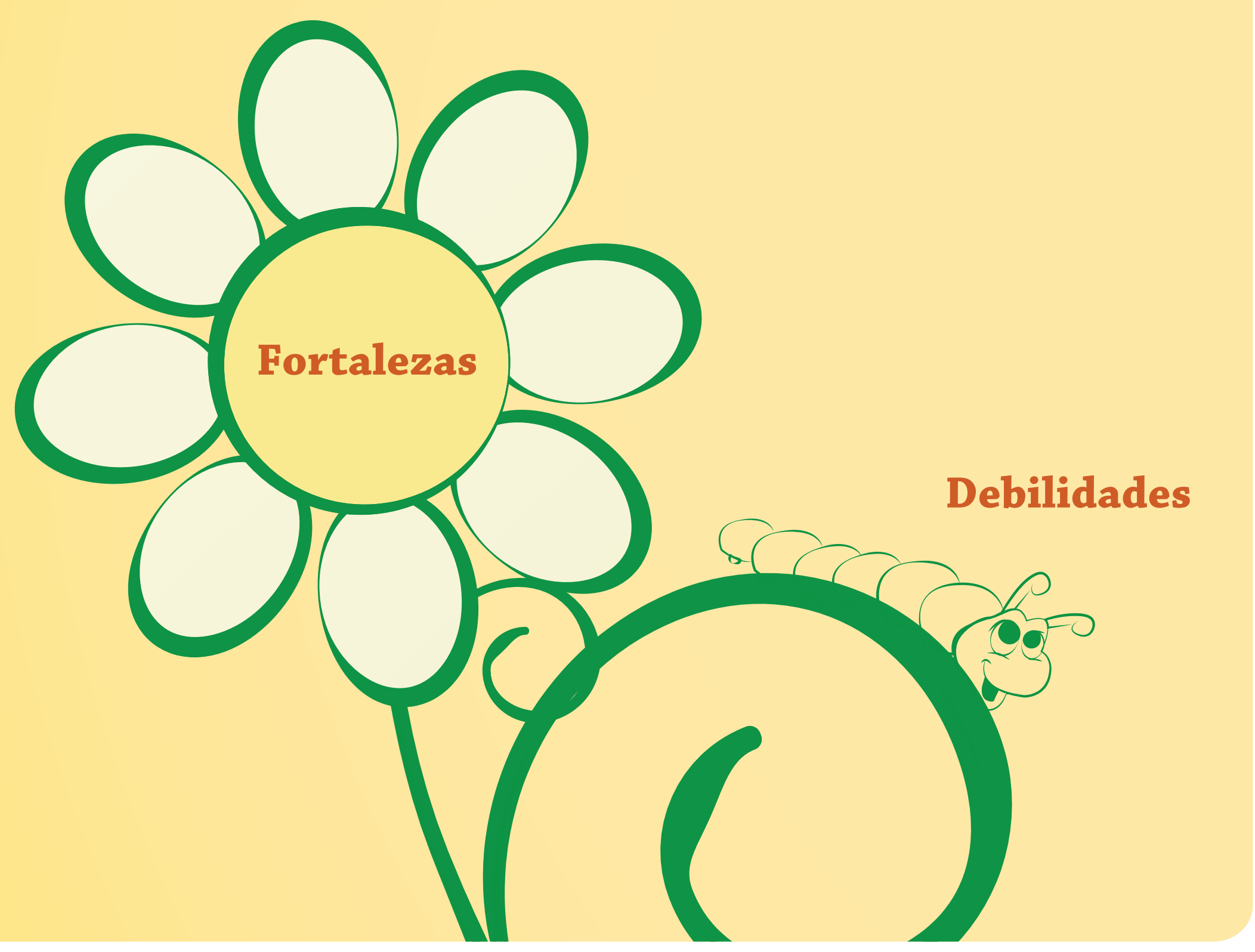


SESIÓN 3 - Cómo me valoro a mí misma

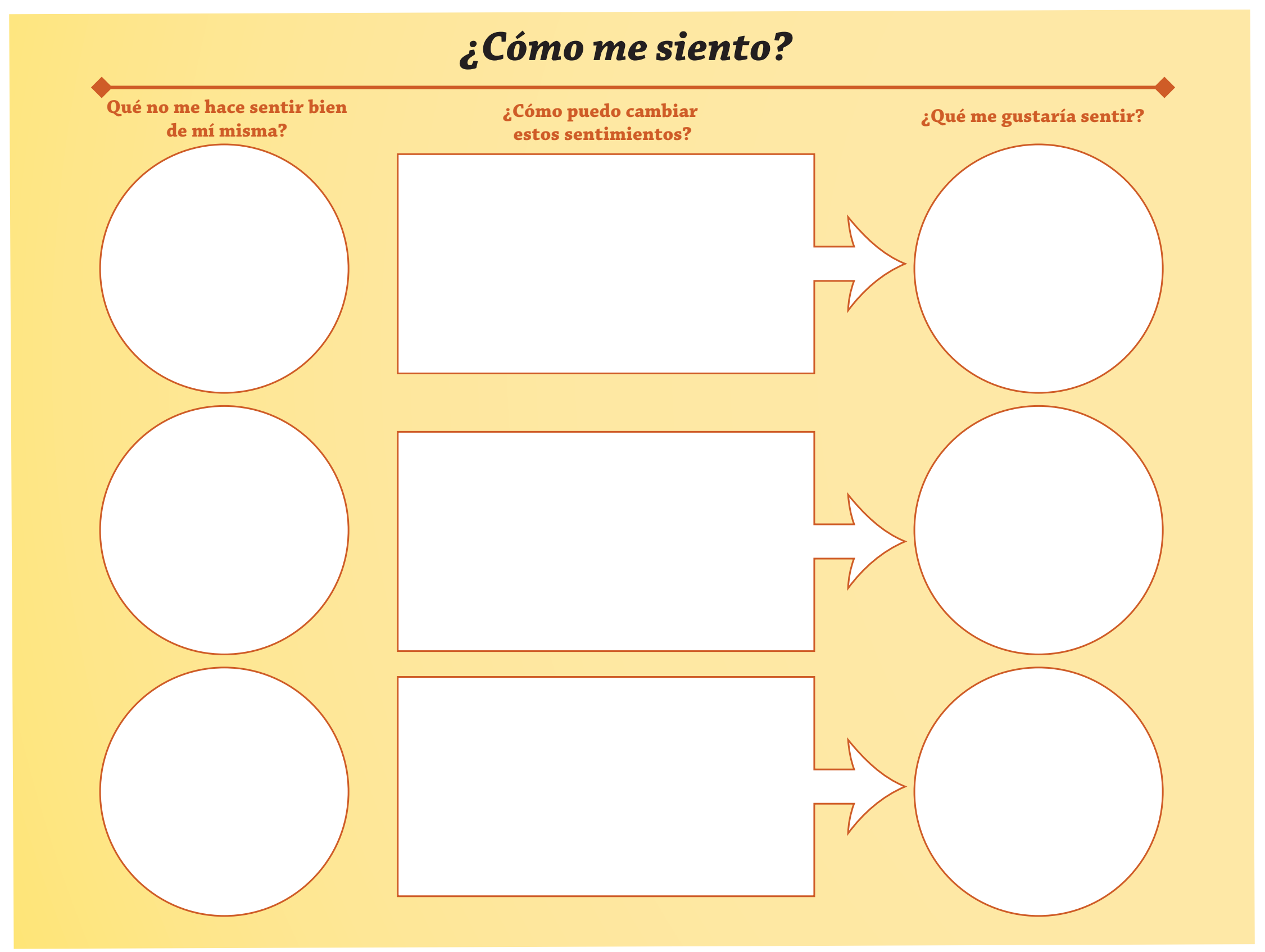




\section{SESIÓN 4 - Derechos Humanos}

\section{Derechos universales}

Todo individuo tiene derecho a la vida, a la libertad y la seguridad de su persona.

$\downarrow$ Todo individuo tiene derecho a la libertad, nadie estará sometido a esclavitud ni a servidumbre.

$\downarrow$ Tienes derecho a la igualdad y a no ser discriminada

Tienes derecho a disfrutar de una vida libre de violencia.

Tienes derecho a la información y educación.

Tienes derecho a la salud física y psicológica.

Tienes derecho a participar en la vida política de tu comunidad.

Tienes derecho a la vivienda, la alimentación y el vestuario.

$\uparrow$ Tienes derecho al trabajo.

Tienes derecho a una nacionalidad y un nombre.

Tienes derecho a la información y educación en sexualidad.

Tienes derecho a un servicio de salud sexual reproductiva accesible, adecuada y de calidad. 


\section{SESIÓN 5 - Guía Mujeres y Hombres}

\section{Guia: Mujeres y Hombres}

\begin{tabular}{|l|l|l|}
\hline & Género ó Sexo & \\
\hline $\begin{array}{l}\text { La mujer no desarrolla una profesión. } \\
\text { La mujer no necesita estudiaro nos afecta? }\end{array}$ & \\
\hline La mujer queda embarazada. & \\
\hline Una buena mujer tiene muchos hijos. & \\
\hline $\begin{array}{l}\text { La herencia de la familia la reciben los } \\
\text { hombres. }\end{array}$ & \\
\hline $\begin{array}{l}\text { La suegra de una mujer tiene que decirle } \\
\text { qué hacer, orientarla y controlarla. }\end{array}$ & \\
\hline $\begin{array}{l}\text { La mujer debe casarse joven para que la } \\
\text { mantenga su esposo y pueda hacer una } \\
\text { familia. }\end{array}$ & \\
\hline $\begin{array}{l}\text { Un hombre necesita tener a su esposa } \\
\text { y además a otras mujeres. }\end{array}$ & \\
\hline $\begin{array}{l}\text { Los hombres no pueden cuidar a sus } \\
\text { hijos y por eso sólo lo pueden hacer las } \\
\text { mujeres. }\end{array}$ & \\
\hline $\begin{array}{l}\text { Un hombre de verdad tiene } \\
\text { hijos varones. }\end{array}$ & \\
\hline $\begin{array}{l}\text { Las tareas del hogar son responsabilidad } \\
\text { de la mujer y no del hombre. }\end{array}$ & \\
\hline
\end{tabular}


SESIÓN 6 - Pensando en mi identidad más allá del género

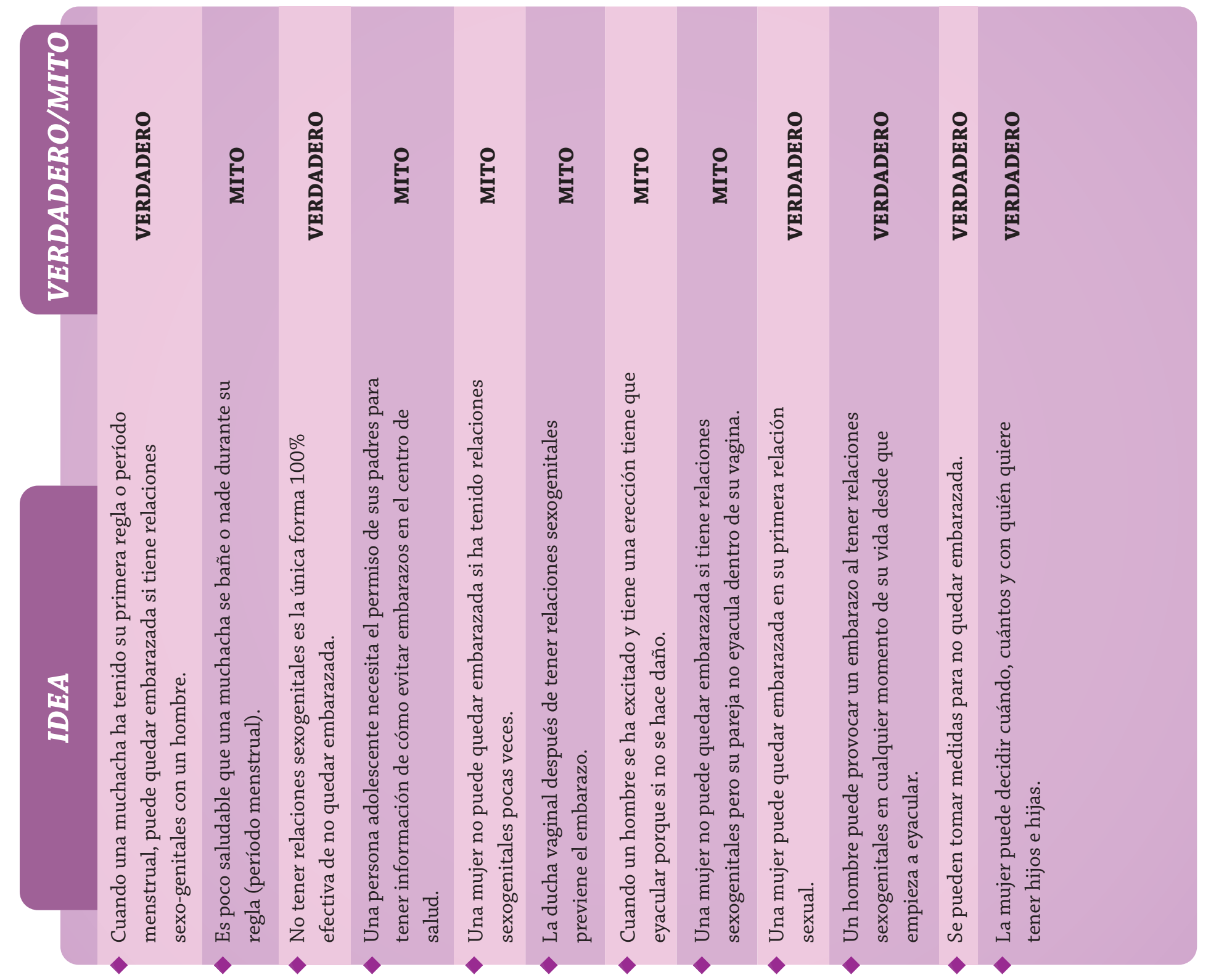


SESIÓN 7 - Tomo decisiones para salir de situaciones peligrosas

¿Qué situación peligrosa estaremos afrontando? Nuestra decisión para prevenir los peligros 